\title{
Computer parametric designing in Blender software for creating 3D paper models
}

\author{
Kremena Cankova ${ }^{1}$, Tihomir Dovramadjiev ${ }^{1}$ and Ginka Jecheva ${ }^{1}$ \\ 1-Technical University of Varna, Department Industrial Design , 9010, 1 Studentska Street, Varna, Bulgaria \\ Corresponding author contact: kremenacankova@abv.bg
}

\begin{abstract}
In the contemporary conditions, the implementation of computer parametric design to facilitate the design of $3 D$ paper models is successfully realized using modern technological tools such as the free software Blender. Through the convenient interface of the program, the modeling of the desired three-dimensional shapes is greatly facilitated. This also applies to the automated process of constructing a drawing of the resulting polygonal $3 D$ models, which in the future are assembled into three-dimensional paper models. This paper describes in detail the process of finedesigning $3 D$ paper models using specific exemplary primitive, text, and with relatively complex form.
\end{abstract}

Keywords: 3D, Blender, parametric, paper, models

\section{Introduction}

3D paper models find a versatile application in practice. Their scope covers various areas such as art-design (Molina i-link, 2017), sculpture (Straub \& Hartmut, 2011), advertisements, decorations, jewelry (Karen i-link, 2017), models of architectural elements, modern and historical buildings and facilities (Xian-Ying, Chao-Hui, Shi-Sheng, Tao \& Shi-Min, 2010). They are used to recreate completely urbanized and geographic areas (Tau \& Lahr, 1991; Tau \& Laslie, 1990), important for the packaging industry (Roth \& Wybenga, 2012) etc. Depending on the specific activity, the design and construction of 3D paper models is done by manual work, which requires certain technical skills (Birmingham, 2006; Conrado, Sang \& Yum 2014; Райчев, 2002) or it can be automated by using different technical means. A very good modern technological tool is the Blender software (Dovramadjiev, 2015). It is fully accessible with its free and open source license (Alecu, 2010). The Blender program is distributed based on GNU General Public License (Blender - GNU i-link, 2017; GPL i-link, 2017).

The Blender program is an environment for developing 3D polygonal mesh models (Blain, 2012; Chopine, 2011; Chronister, 2009 \& 2011; Wickes, 2009; Прахов, 2009). This is the basis on which additional capabilities have been built with different strands - both pledged and externally available add-ons. In the process of releasing new software versions, additional capabilities are enriched with new and / or sophisticated features. The capabilities of additional add-ons applications are growing in variety. Important clarification about external add-ons is their direct purpose for the particular version of Blender. Some of them are sustainable in time and are active in both the older and the newer ones. Similarly, the integration of the specialized application (Export: Paper Model (.svg)) to make 2D print sheets from 3D mesh models in Blender's environment originally appeared as an external add-on by author Addam Dominec. The application is completely free of charge on the Internet: https://wiki.blender.org/index.php/Extensions:2.6/Py/Scripts/Import-Export/Paper_Model.

Downloading the application (file name: io_export_paper_model.py) and its subsequent integration for the newer versions of Blender is not necessary due to the fact that the application is already embedded in the basic package of the most current version of Blender 2.79 (December 2017; 
https://www.blender.org/download/). Activating the application Export: Paper Model application in Blender software is shown in figure 1.

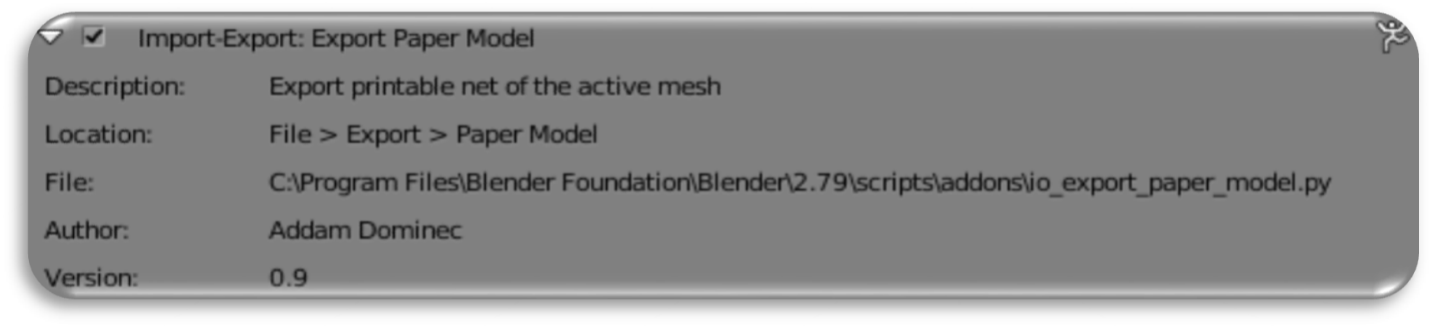

Fig. 1. Activating the application Export: Paper Model add-on.

\section{$2 \quad$ Materials and Methods}

In the present study, using the Blender program and parameterization, the following threedimensional mesh models will be developed:

2.1 Three-dimensional primitive - cub;

2.2 Three-dimensional letters - Text;

2.3 Three-dimensional models with relatively complex shape - diamond (2.3.1) and gem (2.3.2).

After receiving the desired three-dimensional shape of the models, they will be automatically unfolded on a 2D drawing. The received files have a * .pdf extension. They contain high-quality drawing features including dull lines (for cropping), dashed lines (for folding), glueing areas, inscriptions, "islands", and reinforcing bonding gaps (integrating larger volumes).

The exact sizing of the patterns is set in the Scene panel by selecting the unit of measure. By default, Blender works with a unit of measure - meter. It is also good to consider the printing device and the shape of the sheet.

\subsection{Development of 3D primitive - cub}

The Blender program is set so that after the work area is insulated and released, a threedimensional cube model (Fig. 2a) is positioned with the parameters shown in Table 1.

Table 1. Parameters of 3D model-cube.

\begin{tabular}{|c|c|c|}
\hline Coordinates & Scale & Dimension $/ \mathbf{m}$ \\
\hline$X$ & 1 & 2 \\
\hline$Y$ & 1 & 2 \\
\hline$Z$ & 1 & 2 \\
\hline
\end{tabular}

Using the application Export: Paper Model, the cube model is exported to a * .pdf file format. This is done by using File-> Export $\rightarrow$ Paper Model (svg) and specifying a folder where the file name is entered. Figure $2 \mathrm{~b}$ shows the model's completed loop. 


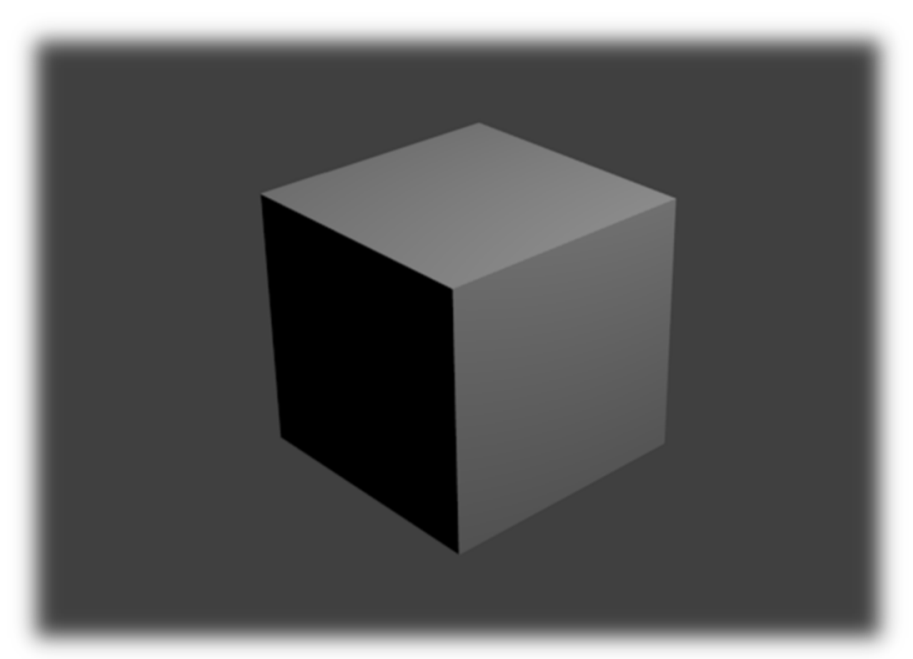

(a)

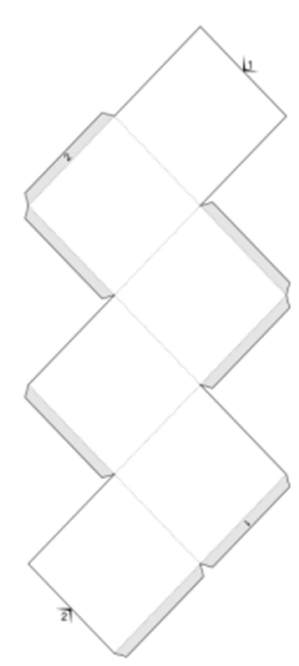

(b)

Fig. 2. Activating the application Export: Paper Model add-on (a) 3D model cube, (b) unfold.

\subsection{Developing three-dimensional letters -Text}

Three-dimensional text in Blender is obtained using Add $\rightarrow$ Text and manually displays the desired word, a single letter or a character in Edit Mode. Object Data defines extruding values. In this case: Modification $\backslash$ Extrude: 0.1 (Fig. 3).

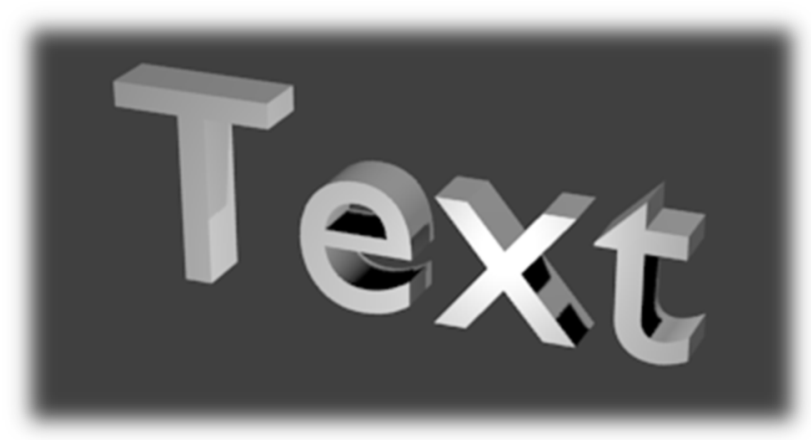

Fig. 3. Three-dimensional model - „Text”.

In order to create the paper unfolding, it is desirable that the letters have to be generated individually, thereby undergoing a process of reconstruction of the polygonal mesh. For the selected Object letter, select Convert to and Mesh from Curve / Meta / Surf / Text (Alt C). The result shows that the resulting polygon mesh of the letter is poorly ordered. Therefore, in the modifier section, Remesh is selected and in the Object Mode mode the polygonal mesh is reconstructed. In order to obtain a precise and well-built mesh, it is necessary to select all elements of the 3D model in Edit mode before using the Remove Doubles. Fig. 4 shows the initially constructed letter T (4a), Remesh (4b) and the resulting unfolding (4c). 


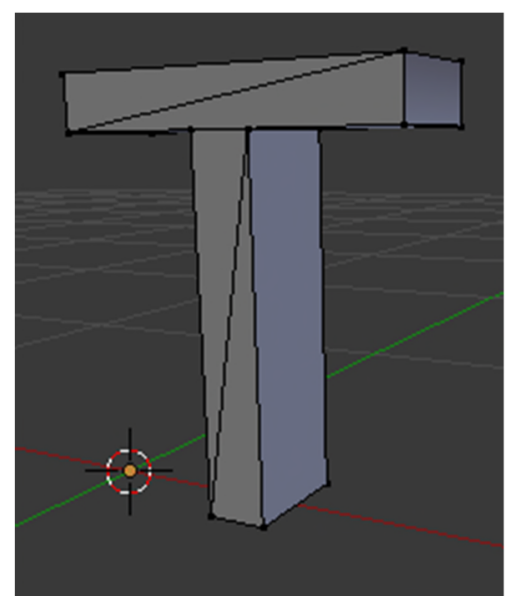

(a)

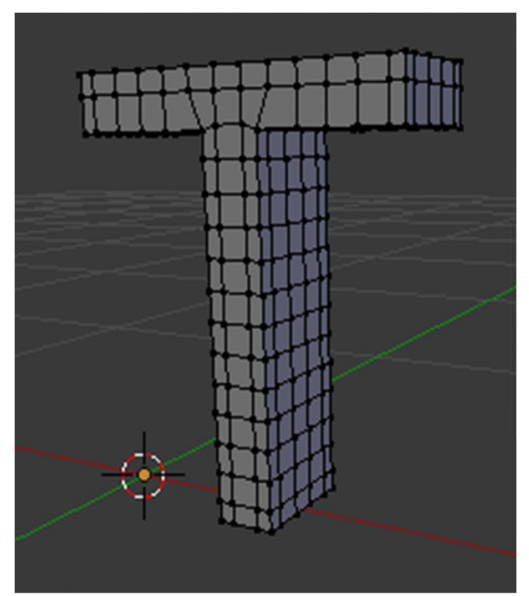

(b)

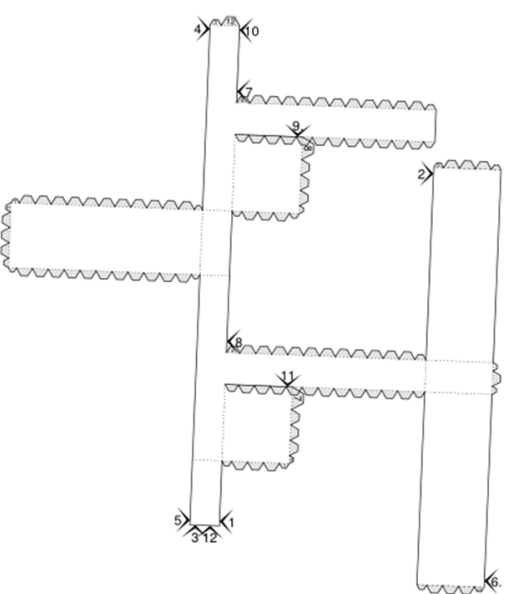

(c)

Fig. 4. Three-dimensional model - letter "T" - part of "Text" (a) polygonal mesh resulting from conversion, (b) reconstructed polygonal mesh, (c) unfold.

The unfolding of the other letters of "Text", respectively "e", " $\mathrm{x}$ " and " $\mathrm{t}$ " are shown in fig.5. It is important to specify that the images have to be proportionate when printing - in this case they are arranged disproportionately in a row.

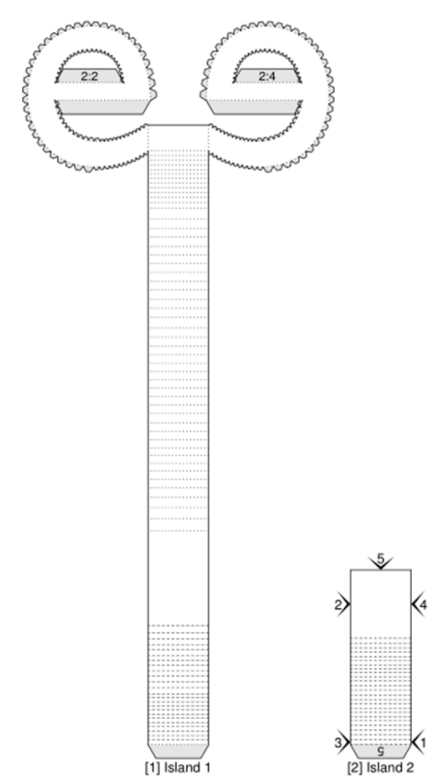

(a)

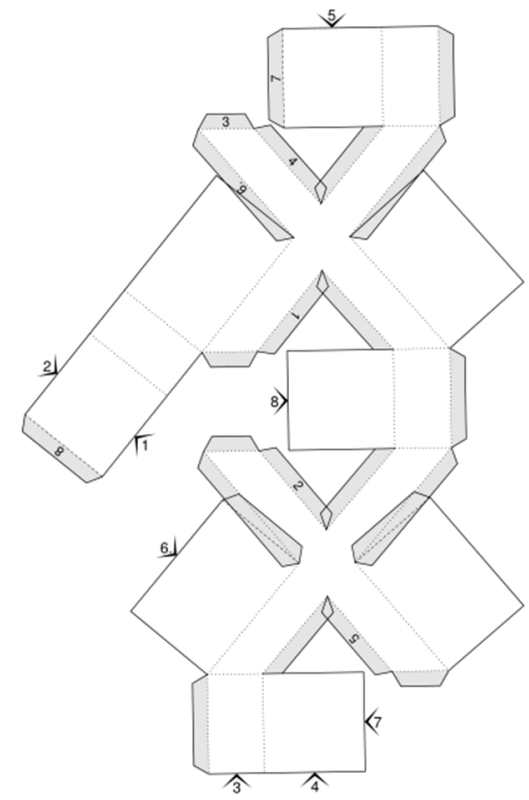

(b)

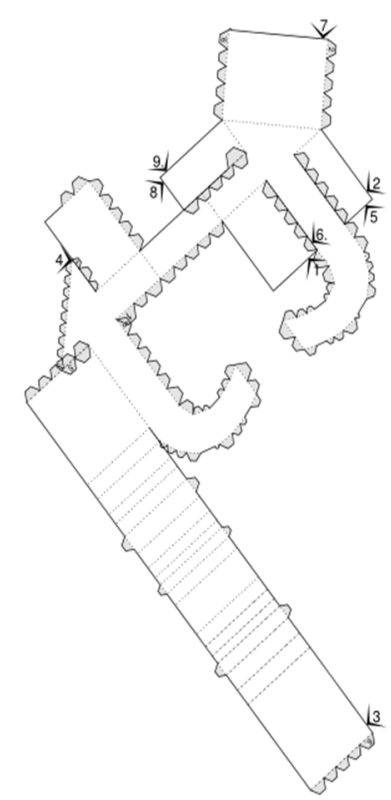

(c)

Fig. 5. Letter extension - disproportionate (a) "e", (b) "x", (c). 


\subsection{Three-dimensional models with a relatively complex shape}

In the process of creating extensions from 3D computer models, the application Export: Paper Model tries to get the most out of the information mesh. In the presence of multiple polygons that exceed the maximum of expansion possibilities, the three-dimensional model needs to be optimized to admissibility. In order to check the performance of Blender and the application Export: Paper Model, two models with a relatively complex shape - diamond (2.3.1) and gem (2.3.2) have been parametrically developed.

\subsubsection{Creating a 3D computer diamond model (Diamond) and its unfolding}

Creating a 3D model of diamond in a Blender environment is a complicated process. So for convenience in the Blender Add Mesh advanced applications, there is the Add Mesh: Extra Objects app. By doing this, the geometry of the diamond becomes parametric and not conventional by manual modeling. The parameters of the newly created 3D diamond pattern are shown in Table 2.

Table 2. Parameters of the 3D model - diamond.

\begin{tabular}{|c|c|}
\hline Operator Presets & Parameters $/ \mathbf{m}$ \\
\hline Segments & 32 \\
\hline Girdle Radius & 1 \\
\hline Table Radius & 0.6 \\
\hline Crown Height & 0.35 \\
\hline Pavilion Height & 0.8 \\
\hline
\end{tabular}

The finished 3D computer model of the diamond is shown in fig. 6 (a) in a mesh variant and fig. 6 (b) a rendered version. The resulting unfolding using the Export: Paper Model application is shown in fig.6 (c).

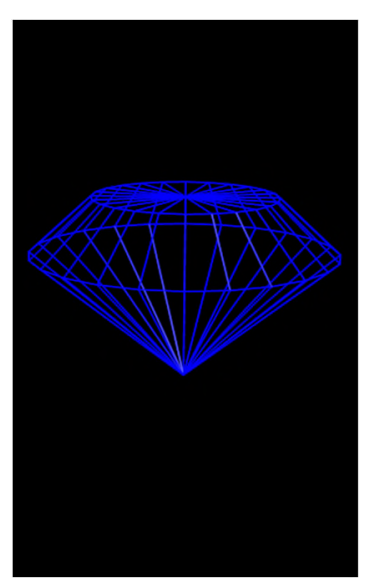

(a)

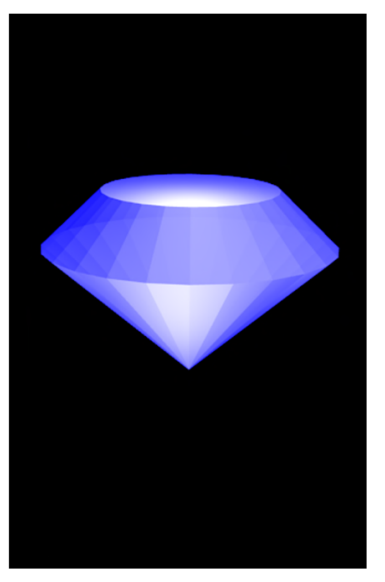

(b)

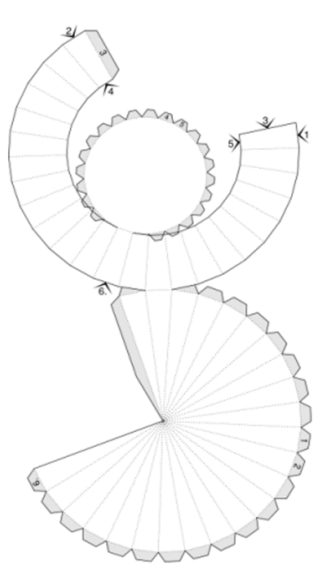

(c)

Fig. 6. 3D model of the diamond (a) mesh variant of the view, (b) rendered version of the view, (c) unfold.

\subsubsection{Creating a 3D computer model of Gem and its unfolding.}

The process of creating the 3D computer model of the gem is identical to the diamond, using the geometry "Gem". The parameters of the newly created 3D model of the gem are shown in Table 3. 
Table 3. Parameters of the 3D model - gem.

\begin{tabular}{|c|c|}
\hline Operator Presets & Parameters $/ \mathbf{m}$ \\
\hline Segments & 8 \\
\hline Girdle Radius & 1 \\
\hline Table Radius & 0.6 \\
\hline Crown Height & 0.44 \\
\hline Pavilion Height & 0.90 \\
\hline
\end{tabular}

The finished 3D computer model of gemstone is shown in fig. 7 (a) in a mesh variant and fig.7 (b) a rendered variant. The resulting unfolding using the Export: Paper Model application is shown in fig. 7 (c).

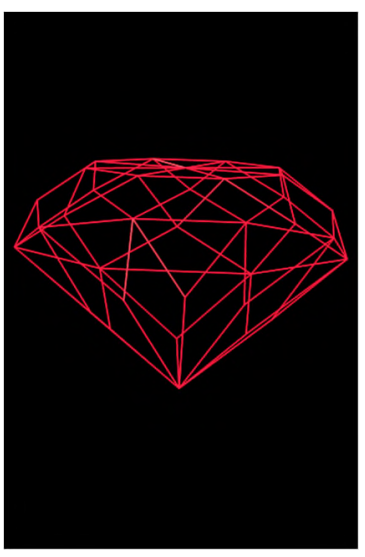

(a)

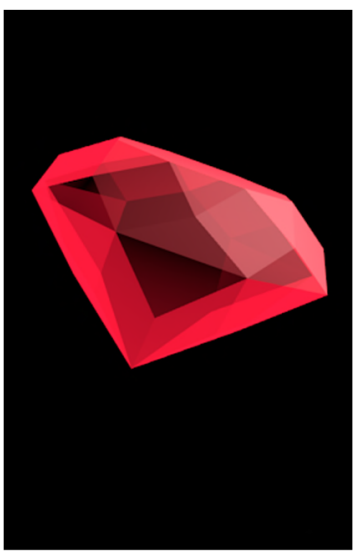

(b)

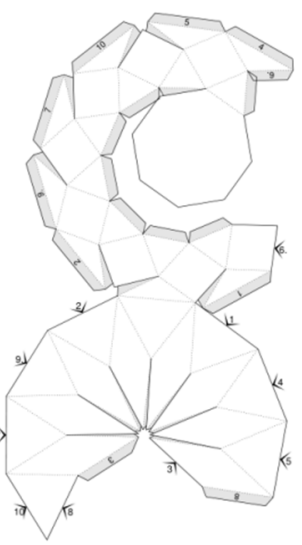

(c)

Fig. 7. 3D model of the gem (a) mesh variant of the view, (b) rendered version of the view, (c) unfold.

\section{$3 \quad$ Results}

The resulting unfoldings are assembled by hand or machine processing. An example of a real assembled result of the used diamond and gemstone paper samples is shown in fig. 8 .

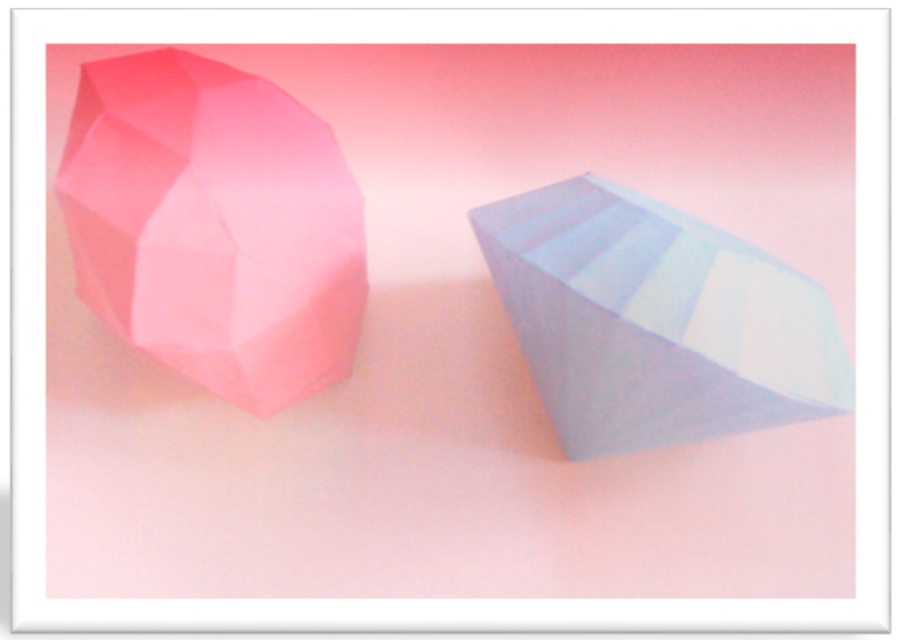

Fig. 8. The resulting assembled paper folds of diamond and gem. 
In this study, the process of designing sample paper models has been closely followed using the Blender software resource, which by means of the specialized application Export: Paper Model automatically generates 3D polygonal mesh computer models. Various 3D computer models with different geometric complexity have been parametrically constructed. The opportunities used in the study prove the effectiveness of modern technological tools used to create accurate paper models.

\section{References}

Alecu F. (2010). Blender Institute - the Institute for Open 3D Projects. Open Source Science Journal Vol. 2, No. 1, Economic Informatics Department, ASE Bucharest, Romania, p. 36 - 45.

Birmingham Duncan (2006). Pop-Ap! A Manual of Paper Mechanisms. Tarquin Publications ISBN: 1899618090, UK, p. 96.

Blain M. J. (2012). Computer Modeling and Animation. The Complete Guide to Blender Graphics. Taylor \& Francis Group, LLC. ISBN:13: 978-1-4665-1704-2. UK.

Chopine A. (2011). 3D Art Essentials The Fundamentals of 3D Modeling, Texturing, and Animation. Elsevier, ISBN: 978-0-240-81471-1, USA, p. $249-252$.

Chronister J. (2009). Blender $3 D$ Basics. 3rd Edition, Creative commons attribution-Non Commercial-share alike 3.0 Unported License, p.146.

Chronister J. (2011). Blender Basics 2.6 .4-rd edition. Cdschools eBook, p. 178.

Conrado R. Ruiz Jr. Sang N. Le Jinze Yu Kok-Lim Low (2014). Multi-style Paper Pop-up Designs from $3 D$ Models. Department of Computer Science, National University of Singapore. Computer Graphics Forum. The Eurographics Association and John Wiley \& Sons Ltd. Published by John Wiley \& Sons Ltd. EUROGRAPHICS Volume 33, Number 2.

Dovramadjiev T. (2015). Modern accessible application of the system Blender in $3 d$ design practice. International scientific on-line journal "SCIENCE \& TECHNOLOGIES". Publishing House "Union of Scientists - Stara Zagora", ISSN 1314-4111; Bulgaria, p. 10 - 13.

Straub Raphael and Prautzsch Hartmut (2011). Creating Optimized Cut-Out Sheets for Paper Models from Meshes. Karlsruhe Reports in Informatics 36. Edited by Karlsruhe Institute of Technology, Faculty of Informatics, ISSN 2190-4782.

Roth Laszlo and Wybenga L. George (2012). The packaging Designer's Book of Patterns. Fourth Edition. John Wiley \& Sons, Inc. USA. ISBN: 978-1-118-42084-3,704 pages.

Tau Rho Alpha and and Lahr C. John (1990). How to construct seven paper modelsthat describe faulting of the Earth. UNITED STATE DEPARTMENT OF THE INTERIOR GEOLOGICAL SURVEY. Open-file Report 90-257 A. 
Tau Rho Alpha and Leslie Gordon C. * (1991). Make your own paper model of a volcano. Open-File Report 91-115A

Wickes D. R. (2009). Foundation Blender Compositing. ISBN-13 (pbk): 978-1-4302-1976-7, USA.

Xian-Ying Li 1 Chao-Hui Shen 1 Shi-Sheng Huang 1 Tao Ju 2 Shi-Min Hu 1(2010). Automatic Paper Architectures from 3D Models. 1 TNList, Department of Computer Science and Technology, Tsinghua University, Beijing. 2 Department of Computer Science and Engineering, Washington University in St. Louis.

Прахов А. А. (2009). Blender: 3D-моделирование и анимащия. СПб.: БХВ, ISBN 978-5-97750393-8, Русия, 272 с: ил

Райчев Румен (2002). Структурна комбинаторика. Анубис. България, ISBN: 954-426-469-8.

\section{Online sources:}

The software Blender under the GNU General Public License /GPL, or "free software"/ (2017). Available information on: https://www.blender.org/about/license/

GNU General Public License (2017). Available information on: http://www.gnu.org/copyleft/gpl.html

Karen Elizabeth Halbrook (2017). Create 3D paper sculpture jewelry, home decor and gifts. bayoudreamer.com/pdfs/paper_jewelry.pdf

Molina Carlos (2017). Paper \& Digital Artistry. http://carlosnmolina.com/ 